\title{
GRADUACIÓN DE MÉDICOS \\ Palabras del Dr. Gabriel Burgos Mantilla Viceministro de Educación Superior
}

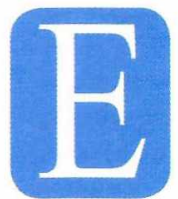

n primer lugar, un profundo agradecimiento a las directivas de la institución por invitarme a este acto de graduación que congrega a la comunidad académica, padres de familia, docentes y estudiantes de la Fundación Universitaria de Ciencias de la Salud. Desde el Ministerio de Educación, como observadores permanentes del desempeño y del mejoramiento continuo del sector de la educación superior, resaltamos el compromiso de esta institución en la implementación de proyectos innovadores, incluyentes y de alta calidad.

No es un secreto para nadie que hoy nos encontramos inmersos en la denominada "sociedad del conocimiento" en la que la educación, la ciencia y la tecnología son las herramientas fundamentales para el desarrollo económico y social de los pueblos, unidas a un manejo eficiente, equitativo y respetuoso del medio ambiente.

Hoy las ventajas competitivas de las naciones ya no se heredan en forma de riquezas físicas, sino que se desarrollan de manera prioritaria mediante la construcción de una persona humana calificada. El esfuerzo requerido para desarrollarlo supone diversas medidas, entre las cuales juega un papel preponderante mejorar la calidad, equidad y acceso a la educación. En este sentido, hay consenso sobre la necesidad de impulsar al estudiante como sujeto activo del aprendizaje, de manera que adquiera no solo una mera acumulación de saberes en una disciplina, sino una serie de competencias referidas a ésta.

En esta dinámica, cobra relevancia la necesidad de revisar la oferta de educación en términos de

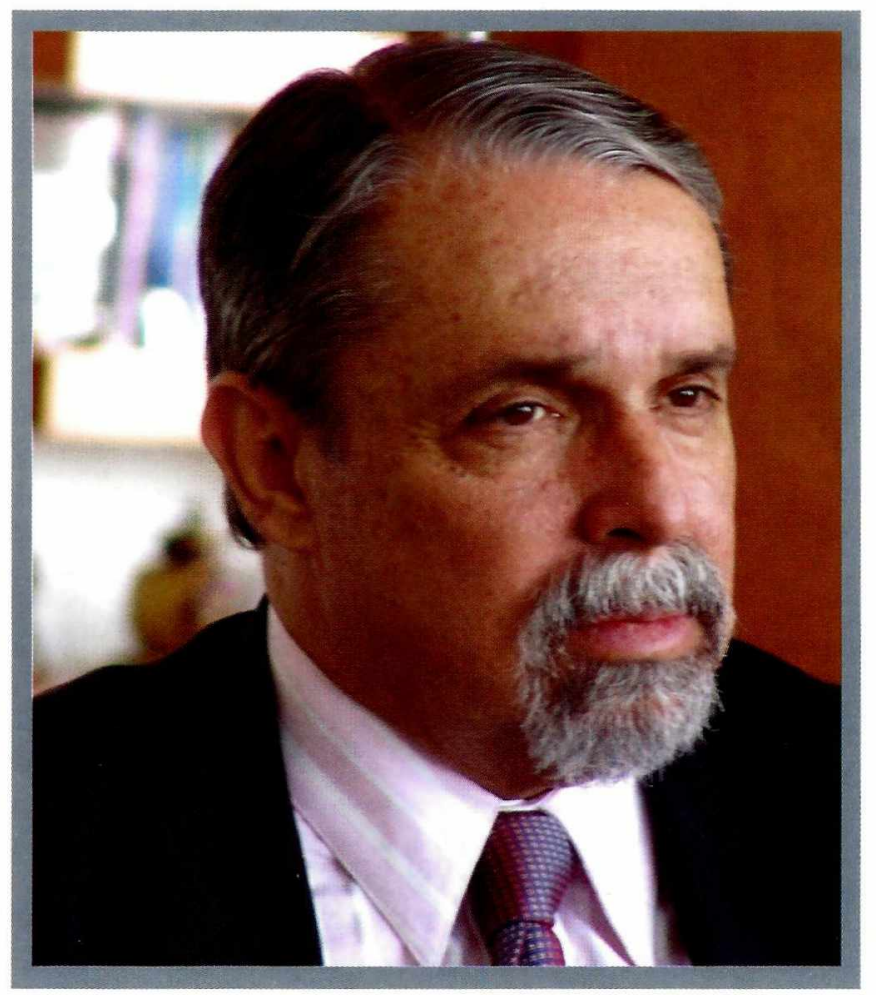

currículos flexibles que respondan a la diversidad de las demandas de calificación que la sociedad del conocimiento determina. Actualmente, nadie puede contar con que el acervo inicial de conocimientos constituidos en la juventud le baste para toda la vida, pues la rápida evolución del mundo exige una actualización permanente del saber.

Como respuesta a esta necesidad, el Ministerio de Educación formuló el plan sectorial La revolución educativa, el cual se convirtió en uno de los pilares fundamentales de la política social de este gobierno y propuso metas específicas en cobertura, calidad, eficiencia y pertinencia, con las que estamos enfrentando el retraso educativo que traía el país. 
En cobertura en educación superior el reto es grande, pero la ampliación es indispensable para lograr una verdadera revolución en equidad, bienestar social y competitividad. Para el 2010 esperamos alcanzar una tasa de cobertura bruta del 34\% y para el 2019 del $50 \%$, hoy apenas llegamos al 27\%. También haremos un gran esfuerzo por aumentar la participación de la educación técnica y tecnológica al menos al $40 \%$ en el 2010 y al $60 \%$ en el 2019 con el fin de garantizar una formación pertinente con el desarrollo del país.

La apuesta por ampliar el acceso de la población a un sistema de educación incluyente, viene acompañada por políticas consistentes y rigurosas en materia de calidad que se traducen para el caso de educación superior, en el Sistema de Aseguramiento de la Calidad, como un esfuerzo conjunto con las instituciones por consolidar un sistema que permita un mayor acceso de la población a la formación con altos estándares de calidad. Nos hemos propuesto que en el año 2010 todos los programas de educación superior tengan registro calificado. Con este fin pusimos en práctica "el ciclo de calidad" sostenido en tres pilares: la definición de estándares de competencias, la aplicación de pruebas que miden los avances de las instituciones en todos los niveles y la puesta en marcha de planes de mejoramiento y de sistemas de aseguramiento de la calidad.

Para este proceso se han diseñado varios componentes: la verificación de las condiciones mínimas de calidad para el registro calificado, obligatorias para todas las instituciones y programas; la acreditación voluntaria y de alta calidad y así mismo, la acreditación institucional. El programa de medicina de la Fundación Universitaria de Ciencias de la Salud obtuvo registro calificado en 2003 y los tres programas de pregrado restantes y 21 especializaciones durante años posteriores; el programa de enfermería cuenta con acreditación de alta calidad.

La exigencia del registro calificado para todos los programas de educación superior y la acreditación voluntaria de alta calidad, han contribuido a la incorporación del concepto de calidad en todas las áreas misionales de las instituciones. Durante el último año evaluamos las condiciones mínimas de calidad de 1.300 programas de educación superior, evaluación en la que intervienen pares académicos y CONACES, con lo cual el $78 \%$ de la oferta de programas de pregrado y el $67 \%$ de postgrado cuentan con una garantía pública básica de calidad. Asimismo, 130 programas de educación superior han logrado la acreditación en alta calidad y al finalizar el cuatrienio, la meta es que 440 programas adicionales cuenten con este reconocimiento a su excelencia para llegar a 900 en total.

Otros componentes importantes del sistema son los exámenes de calidad de la educación superior ECAES y el Observatorio del Mercado Laboral que ofrecerán información acerca del resultado final del proceso de formación en cuanto a competencias y conocimientos por un lado, y la incorporación de los egresados al mundo laboral.

En conjunto, los resultados de los estudiantes muestran que hemos ampliado el número de graduados en educación superior, evaluados por ECAES, de 58.900 en 2002 a 81.955 en 2006. En el año 2004, el puntaje promedio de las pruebas ECAES de la Fundación Universitaria de Ciencias de la Salud fue superior al promedio nacional.

Por su parte, el Observatorio Laboral para la Educación representa uno de los puntos más importantes dentro de la política de calidad y va muy ligado a la pertinencia. El objetivo del Observatorio es construir un sistema de seguimiento a los graduados que genere información para orientar a los profesionales, instituciones de educación superior, al sector productivo, aspirantes a la educación superior y a la sociedad en general, sobre la probabilidad de emplear a los graduados y la información cualitativa sobre la pertinencia del área de formación vs. la ocupación del graduado.

El Observatorio cuenta en la actualidad con información, por núcleos básicos de conocimiento, sobre la 
probabilidad de emplear 706.654 titulados de educación superior para el período entre 2001 y 2006, con datos relevantes sobre ingresos promedios, tasa de ocupación y tiempo que le toma a un graduado insertarse al mercado laboral.

Según cifras del Observatorio el 31.9\% de los graduados pertenecen al área de economía, administración, contaduría y afines, el $24.7 \%$ a ingeniería, arquitectura, urbanismo y afines, $9.3 \%$ a ciencias de la salud y el área con menos graduados es agronomía, veterinaria y afines con el 1.4\%. Adicionalmente, la encuesta de seguimiento aplicada a 5.067 graduados en educación superior entre el 2000 y el primer semestre del 2006, refleja que el $58 \%$ dura menos de seis meses en conseguir su primer empleo y el $89 \%$ menos de un año. El $47 \%$ de los egresados de ciencias de la salud, toman menos de seis meses en conseguir su primer empleo y el $82 \%$ menos de un año. Por otro lado, la tasa de cotización al sistema general de seguridad social para medicina es del 85,6\% para formación universitaria y del $86.8 \%$ para nivel de especialización.

La reflexión que he hecho a través de este discurso tiene que ver con nuestra visión sobre el futuro de los sistemas de educación, los avances, los desafíos y la imperativa velocidad de la renovación del saber y del saber hacer. Frente a lo anterior, los gobiernos y la academia deben ser conscientes de la responsabilidad que les asiste. Una responsabilidad orientada a garantizar el desarrollo de una gestión académica eficaz y eficiente; una capacidad permanente de autoevaluar la calidad de la formación y el intercambio, movilidad y reconocimiento a nivel nacional e internacional.

Por último, las palabras sinceras y afectuosas de felicitación son para ustedes, queridos jóvenes graduandos, nuevos profesionales de Colombia. Qué felicidad se siente al llegar a la cima, al realizar los sueños, al alcanzar lo largamente buscado.

Qué bueno para Colombia contar con ustedes, la vida es una tarea permanente de esfuerzos para cosechar pequeños resultados, pero la permanencia en los esfuerzos, la constancia y la tenacidad, van logrando pequeños resultados, que poco a poco les harán sentir que ustedes y el país están mejorando.

De la misma manera, a los padres de familia mis felicitaciones, yo se que en el esfuerzo que hicieron sus hijos para llegar a esta meta ustedes fueron partícipes, pero hoy deben sentirse contentos y orgullosos. Me uno a su alegría y orgullo. Disfruten de este hermoso día.

Muchas gracias.
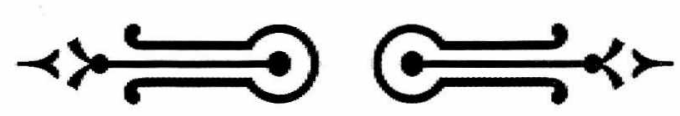